\title{
ChemComm
}

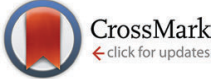

Cite this: Chem. Commun., 2015, 51,12419

Received 19th May 2015

Accepted 24th June 2015

DOI: $10.1039 / \mathrm{c5cc04091d}$

www.rsc.org/chemcomm

\section{Anti-Markovnikov hydroimination of terminal alkynes in gold-catalyzed pyridine construction from ammonia $\uparrow$}

\author{
Liliang Wang, $\ddagger^{a}$ Lingbing Kong, $\ddagger^{a}$ Yongxin Li, ${ }^{b}$ Rakesh Ganguly ${ }^{b}$ and Rei Kinjo*a
}

\begin{abstract}
Gold-catalyzed hydroimination of terminal alkynes, giving rise to anti-Markovnikov adducts concomitant with unstable Markovnikov adducts is described. The elementary step can be applied for the construction of pyridine derivatives from ammonia and alkynes.
\end{abstract}

Acyclic and heterocyclic nitrogen-containing skeletons are ubiquitous in a myriad of naturally occurring compounds as well as in industrial products involving agrochemicals, pharmaceuticals, cosmetics, and fine chemicals. ${ }^{1}$ Hence, the development of efficient methodologies for the formation of carbon-nitrogen bonds has been a subject of considerable interest in synthetic chemistry. In recent years, metalcatalyzed hydroamination, in which $\mathrm{C}-\mathrm{N}$ bonds are formed by direct addition of a nitrogen-hydrogen bond across carbon-carbon multiple bonds, has been represented as a powerful atom-economic tool for the synthesis of nitrogen-containing compounds. ${ }^{2}$ However, control of the regioselectivity is a major problem to be addressed. Thus, as classical textbooks state that the proton forms a bond with the carbon bearing fewer substituents in accordance with Markovnikov's rule, archetypal hydroamination products are also dominated by Markovnikov adducts with a branched skeleton. ${ }^{3}$ Accordingly, the preparation of nitrogen-containing compounds with a linear skeleton by direct anti-Markovnikov hydroamination remains highly challenging. ${ }^{4}$

Since the pioneering work of Beller and co-workers on the first metal-catalyzed anti-Markovnikov hydroamination of olefins in $1999,{ }^{5}$ various methodologies for intermolecular anti-Markovnikov hydroamination using metal catalysts involving alkali metals, ${ }^{6}$ alkaline earth metals, ${ }^{7}$ organolanthanide, ${ }^{8} \mathrm{Ti},{ }^{9} \mathrm{Re},{ }^{10} \mathrm{Ru},{ }^{11} \mathrm{Rh},{ }^{12}$

\footnotetext{
${ }^{a}$ Division of Chemistry and Biological Chemistry, School of Physical and Mathematical Sciences, Nanyang Technological University, Nanyang Link 21, Singapore 637371, Singapore. E-mail: rkinjo@ntu.edu.sg

${ }^{b}$ NTU-CBC Crystallography Facility, Nanyang Technological University, Nanyang Link 21, Singapore 637371, Singapore

$\dagger$ Electronic supplementary information (ESI) available: Experimental and calculation details, and crystallographic information for $\mathrm{LAuCl}, \mathbf{3 h}, \mathbf{3} \mathbf{i}, \mathbf{5 b}, \mathbf{5} \mathbf{g}$ and $\mathbf{6 d}$. CCDC 1051367-1051372. For ESI and crystallographic data in CIF or other electronic format see DOI: $10.1039 / \mathrm{c} 5 \mathrm{cc} 04091 \mathrm{~d}$

\# These authors contributed equally.
}

$\mathrm{Pd},{ }^{13} \mathrm{Cu},{ }^{14} \mathrm{Au}^{15}$ have been reported to date. Although such seminal approaches have led to solid progress, these strategies often involve disadvantages such as limiting the substrate scope, harsh reaction conditions, use of strong bases, or stepwise indirect processes.

In marked contrast to recent advances in the field of hydroamination, the addition of an $\mathrm{N}-\mathrm{H}$ bond of primary imines $\mathrm{HN}=\mathrm{CR}_{2}$ to alkenes and alkynes, namely hydroimination, has rarely been achieved thus far despite the significance of the predicted products, 2-aza-1,3-dienes, as synthetic intermediates for N-heterocycles. $^{16}$ The use of primary imines as nucleophilic substrates is hampered by several difficulties, mainly because of their propensity to behave as electrophiles rather than nucleophiles due to the polarized $\mathrm{C}=\mathrm{N}$ bonds, especially in the presence of Brønsted/Lewis acids. Primary imines are known to act as directing groups by coordinating to metals which induces intramolecular $\mathrm{C}-\mathrm{H}$ activation. ${ }^{17}$ In addition, oxidative homo coupling of primary imines also occurs to form an $\mathrm{N}-\mathrm{N}$ bond in the presence of metals. ${ }^{18}$ To prevent such undesired processes, hydroimination has mainly been limited to intramolecular reactions with the geometrically pre-organized substrates (Scheme 1). ${ }^{19}$ Very recently, Zhao et al. first reported nickel-catalyzed intermolecular coupling between internal alkynes and aromatic $\mathrm{N}-\mathrm{H}$ ketimines. ${ }^{20}$ However, employment of terminal alkynes in their system led to alkyne oligomerization instead of the desired hydroimination. Thus, to the best of our knowledge, hydroimination of terminal alkynes is still unknown to date.

Given the importance of $\mathrm{C}-\mathrm{N}$ bonds in synthetic chemistry, the development of general means for the selective formation is imperative. Here, we report gold-catalyzed hydroimination of terminal alkynes, which afforded both anti-Markovnikov and Markovnikov products. We also describe the first example for construction of pyridine derivatives from ammonia and alkynes.

Our protocol for intermolecular hydroimination of terminal alkynes is based on gold catalysis employing primary ketimines $\mathrm{HN}=\mathrm{CR}_{2}$. We envisaged that (a) the soft $\pi$-acidity of gold allows interaction with alkynes effectively prior to ketimines, and (b) the presence of two R-substituents at the imine carbon of ketimines suppresses the attack by nucleophiles kinetically. We also reasoned that incorporation of a bulky ligand into gold 
Previous works

Intramolecular

$\mathrm{Cl}_{3} \mathrm{C}$

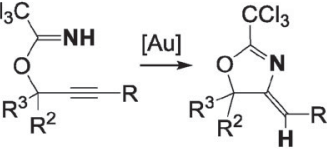

Intermolecular

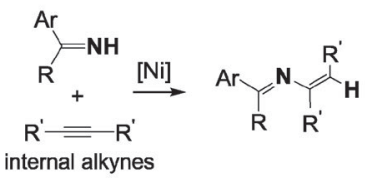

This work

Intermolecular

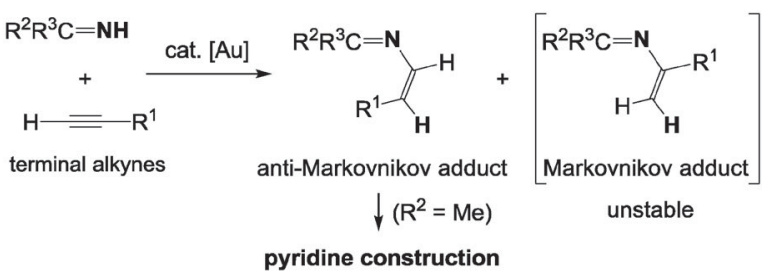

Scheme 1 Metal-catalyzed intramolecular and intermolecular hydroimination.

might minimise the interaction with ketimines by steric repulsion, which will induce selective activation of terminal alkynes rather than the undesired reaction pathway. Among the various ligands available, pyrid-2-ylidene ligands are considered to be good candidates because substitutions at 1- and 3-positions maximize the steric impact at the gold center due to the six-membered ring skeleton. ${ }^{21}$ Pyrid-2-ylidenes are also recognized as strong $\sigma$-donor ligands, which will contribute to promote substrate exchange, necessary for a high turnover in catalysis, as well as the stability of the complex. ${ }^{22}$ Hence, to commence our studies, we designed a novel gold chloride complex supported by a pyrid-2-ylidene ligand $\mathrm{L}$ bearing a 1,3,5-trimethylphenyl group and 3,5-di-tert-butylphenyl groups. When the deprotonation of a pyridinium salt $[\mathrm{L}-\mathrm{H}]^{+}\left[\mathrm{CF}_{3} \mathrm{SO}_{3}\right]^{-}$was performed with lithium hexamethyldisilazide (LiHMDS)(3 eq.), which is followed by the addition of chloro(tetrahydrothiophene)gold(I), a clean reaction occurred, showing a characteristic signal for the carbene carbon at $187.8 \mathrm{ppm}$ in the ${ }^{13} \mathrm{C}$ NMR spectrum. After the products were worked up, LAuCl was obtained as a white solid in $49 \%$ yield (Scheme 2). LAuCl was fully characterized using standard spectroscopic methods, including a single crystal X-ray diffraction study. ${ }^{23} \mathrm{LAuCl}$ is air-stable and can be stored for several months without significant decomposition, both in solution and in the solid state (m.p.; $220{ }^{\circ} \mathrm{C}$ ).

With the precatalyst LAuCl in hand, we next examined its catalytic activity in the hydroimination of terminal alkynes. Recently, Toste and co-workers reported that the gold-catalyzed reaction of phenylacetylene 1a with N,1-diphenylmethanimine $\mathrm{PhN}=\mathrm{CHPh}$ afforded propargylamine. ${ }^{24}$ In marked contrast, the reaction between the two equivalents of 1a and benzophenone imine $2 \mathrm{a}$ with a catalytic

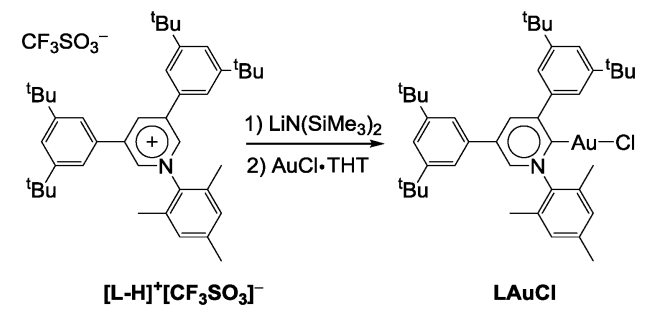

Scheme 2 Synthesis of the gold complex $\mathrm{LAuCl}$. amount of LAuCl produced a mixture of (Z)-1,1-diphenyl- $N$-styrylmethanimine 3a and 1,1-diphenyl- $N$-(1-phenylvinyl) methanimine 4a after 1 hour at $150{ }^{\circ} \mathrm{C}$, and unexpectedly, the yield of the antiMarkovnikov adduct 3a was nearly identical to that of Markovnikov adduct $4 \mathbf{a}$ (3a:4a $\approx 1: 1$ ). We also observed that $4 \mathbf{a}$ gradually decomposed to an unidentified mixture under the reaction conditions (see the ESI $\dagger$ ). Therefore, in order to substantiate the apparent regioselectivity, the reaction was repeated and monitored by NMR spectroscopy. Under the screening reaction conditions, the highest production of the anti-Markovnikov adduct 3a (51\%) was reported after 6 hours (Table 1, entry 1).

To further probe the formation of an anti-Markovnikov product, we performed a ${ }^{13} \mathrm{C}$-labeling experiment with a ${ }^{13} \mathrm{C}$-labeled phenylacetylene $1 \mathbf{a}^{*}$, which decisively afforded $\mathbf{3} \mathbf{a}^{*}$ (Fig. 1a). Control reactions revealed the innocence of potassium tetrakis(pentafluorophenyl)borate $\mathrm{KB}\left(\mathrm{C}_{6} \mathrm{~F}_{5}\right)_{4}$, demonstrating the essential role of the gold complex $\mathrm{LAuCl}$ in this reaction. In fact, the reaction shut down in the absence of the Au precatalyst. With AgOTf instead of $\mathrm{KB}\left(\mathrm{C}_{6} \mathrm{~F}_{5}\right)_{4}$ under similar reaction conditions, the product $3 \mathbf{a}$ was obtained in a lower yield (20\%). When 1-bromo-4-ethynylbenezene $\mathbf{1 b}$ was used (entry 2), the formation of anti-Markovnikov product $\mathbf{3 b}$ was

Table 1 Au-catalyzed hydroimination of terminal arylalkynes ${ }^{a}$

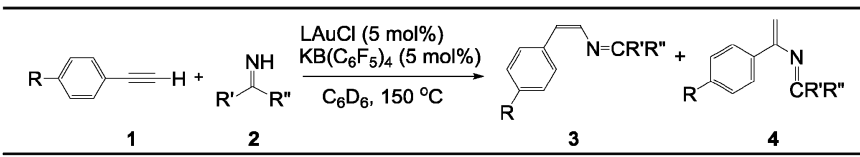

\begin{tabular}{lllll}
\hline & \\
Entry & $\mathbf{1}$
\end{tabular}

${ }^{a}$ Reaction conditions: 1 (0.4 mmol), 2 (0.2 mmol), LAuCl (5 mol\%) and $\mathrm{KB}\left(\mathrm{C}_{6} \mathrm{~F}_{5}\right)_{4}(5 \mathrm{~mol} \%), \mathrm{C}_{6} \mathrm{D}_{6}(0.5 \mathrm{~mL}), 150{ }^{\circ} \mathrm{C}$. ${ }^{b}$ Yields and selectivity were determined by ${ }^{1} \mathrm{H}$ NMR spectroscopy using 1,3,5-trimethoxybenzene as the internal standard. ${ }^{c}$ Isolated yields are given in parentheses. 
(a)

$\mathrm{Ph}-\mathrm{C} \equiv \mathrm{C}^{*}-\mathrm{H}$

(b) Markovnikov
addition

cat. [Au]]

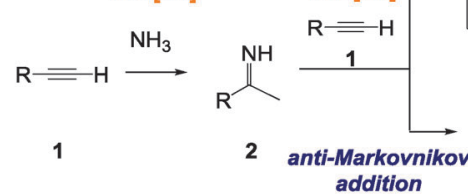

addition

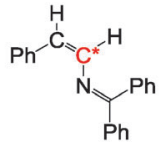

$3 a^{*}$
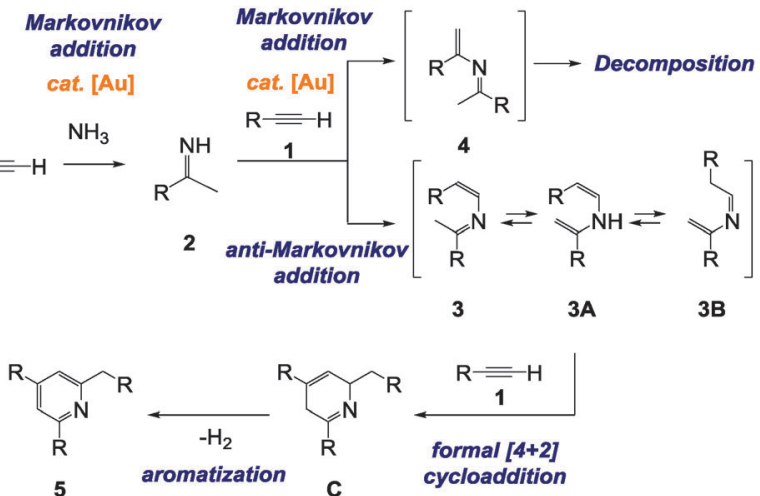

Fig. 1 (a) Representations of ${ }^{13} \mathrm{C}$-labeled phenylacetylene $1 a^{*},(Z)-1,1-$ diphenyl- $N$-styrylmethanimine $3 a^{*}$, and 2-benzyl-4,6-diphenylpyridine $\mathbf{5} \mathbf{a}^{*}$. (b) Proposed reaction pathway for the construction of pyridine $\mathbf{5}$ from alkynes 1 and ammonia.

observed prior to Markovnikov product $\mathbf{4 b}$ even in the early stage of the reaction (after $1 \mathrm{~h} ; \mathbf{3 b}: \mathbf{4 b}=12: 1$ ), and the highest yield $(54 \%)$ of 3b was obtained after 6 hours when $\mathbf{4 b}$ decomposed completely. Treatment of 1a and 4-ethynyltoluene 1c afforded a similar result in which anti-Markovnikov adduct $3 \mathbf{c}$ was formed in $43 \%$ yield after 6 hours (entry 3). These results indicate that the apparent antiMarkovnikov regioselectivity is concomitant with the decomposition of Markovnikov products in addition to the formation of a mixture of other unidentified products, whereas the stability of anti-Markovnikov products encouraged us for further exploration. Reaction of $\mathbf{2 a}$ with an internal alkyne, diphenylacetylene, was also tested, which afforded $N$-(1,2-diphenylvinyl)-1,1diphenylmethanimine in $78 \%$ yield after $22 \mathrm{~h}$ (see the ESI $\dagger$ ).

To test the scope of the hydroimination with respect to imines, we employed various imine substrates. Each reaction was monitored using NMR spectroscopy, and the results for the anti-Markovnikov adduct $\mathbf{3}$ in the highest yield are summarized in Table 1. Standard functional groups are tolerated, including diaryl imines featuring $p$-methylphenyl groups $\mathbf{2 b}, p$-fluorophenyl groups $2 \mathbf{c}$, as well as methyl benzimidate $2 \mathbf{d}$. All imine substrates $2 \mathbf{a}-\mathbf{d}$ examined in this study reacted well with alkynes 1a-c and afforded 2-aza-1,3-dienes 3a-1 in moderate yields. Note that catalytic formation of 2-aza-1,3dienes such as $\mathbf{3}$ and $\mathbf{4}$ from terminal alkynes and imines has never been reported before. It is also noteworthy to mention that under similar conditions, employment of other gold catalysts such as $\left(\mathrm{Ph}_{3} \mathrm{P}\right) \mathrm{AuCl}$ and (IPr)AuCl afforded no and a few $(<10 \%)$ products, respectively. We also examined the reaction of bis-aliphatic imine, 2,2,4,4-tetramethylpentan-3-imine $\left({ }^{t} \mathrm{Bu}_{2} \mathrm{C}=\mathrm{NH}\right)$ with $\mathbf{1 a}$, which gave a complex mixture.

Reaction of 1a with 1-phenylethan-1-imine 2e also proceeded under similar reaction conditions. However, neither $3 \mathbf{m}$ nor $\mathbf{4 m}$ was detected. Instead, only unidentified self-decomposed products of $2 \mathbf{e}$ were observed after the reaction. To our surprise, when a large excess of 1a was used, we obtained 2-benzyl-4,6-diphenylpyridine 5 in $51 \%$ yield after 5 hours, indicating that two equivalents of 1 a were involved in the reaction (Table 1, entry 13). Although we attempted to confirm the reaction intermediates by varying the reaction temperature, time, and substrate ratio, 5a was the only detectable product under any condition. ${ }^{25}$ Presumably, the instability of the corresponding 2-aza-1,3-diene intermediate caused fast cyclization with a second alkyne. The high reactivity of the intermediates may be due to the presence of the sterically less demanding methyl group at the imine carbon, which also could induce tautomerization to transient enamine intermediates. It has already been shown that less-hindered 2-aza-1,3-diene derivatives react with unsaturated molecules to generate cyclic products. ${ }^{16,26}$

Bertrand and co-workers have reported that a catalytic amount of cyclic (alkyl)(amino)carbene gold complexes effectively promotes the addition of ammonia $\left(\mathrm{NH}_{3}\right)$ across alkynes and allenes. ${ }^{27}$ In their study, hydroamination of a terminal arylalkyne, 4-ethynyltoluene, proceeded with Markovnikov regioselectivity, which afforded 1-arylethan-1-imine. On the basis of these results, we attempted the direct synthesis of pyridine skeletons, common components of natural products and pharmaceuticals, ${ }^{28}$ from alkynes and $\mathrm{NH}_{3}$ through the anti-Markovnikov hydroimination-cyclization sequence. We postulate that treatment of terminal arylalkynes $\mathbf{1}$ and $\mathrm{NH}_{3}$ in the presence of our gold catalyst LAuCl also would generate 1-arylethan-1-imines 2 via Markovnikov hydroamination rather than anti-Markovnikov selectivity due to the less bulkiness of the ammonia molecules. The imines formed in situ would further react with a second alkyne in an antiMarkovnikov fashion to give 2-aza-1,3-diene intermediates 3 which would isomerize to $\mathbf{3 A}$ and $\mathbf{3 B}$ followed by cyclization with an additional alkyne. Finally, dehydrogenative aromatization from intermediates $\mathbf{C}$ would afford pyridine derivatives $\mathbf{5}$ (Fig. 1b).

To bear out this hypothesis, 2.5 equivalents of $1 \mathrm{a}$ were treated with $\mathrm{NH}_{3}$ in the presence of the gold complex LAuCl (1 mol\%). To our delight, after 12 hours at $150{ }^{\circ} \mathrm{C}$, 5a was obtained in $43 \%$ yield (Table 2a, entry 1). Interestingly, the spontaneous aromatization by dehydrogenation was induced even without an oxidant. To gain insight into the reaction pathway, we performed further experiments. Reaction of $1 \mathrm{a}$ with a large excess of $\mathrm{NH}_{3}$ exclusively afforded 1-phenylethan-1-imine 2e, confirming that the initial step is a Markovnikov hydroamination of alkyne, affording an enamine which may subsequently tautomerize to imine 2e. Next, a ${ }^{13} \mathrm{C}$-labeling experiment was conducted with $1 \mathbf{a}^{*}$. When $1 \mathbf{a}^{*}$ was employed under the same reaction conditions, $\mathbf{5} \mathbf{a}^{*}$ was produced which supports the proposed reaction pathway (Fig. 1a). The scope of the catalytic reaction was briefly examined for a variety of alkynes 1 (Table 2a). Terminal alkynes with electron-donating as well as electron-withdrawing aromatic groups were well tolerated (Table 2a, entries $2-7,9,10)$. The relatively low yield for $\mathbf{1 h}$ was probably due to the adoption of the extremely strong electron-withdrawing $\mathrm{CF}_{3}$-group (Table 2a, entry 8). 2-Ethynylthiophene and 3-ethynylthiophene also exhibited tolerance to the reaction conditions (Table 2a, entries 11 and 12). Finally, our preliminary test showed that this strategy could be extended to a three-component coupling reaction employing two different terminal alkynes and $\mathrm{NH}_{3}$, which afforded rather complex pyridine derivatives 6 (Table $2 \mathrm{~b}$ ). This result illustrates the potential for application of the preparation of various heterocycles, although 
Table 2 (a) Au-catalyzed pyridine construction from alkynes and ammonia. (b) Au-catalyzed three-component coupling reaction ${ }^{a}$

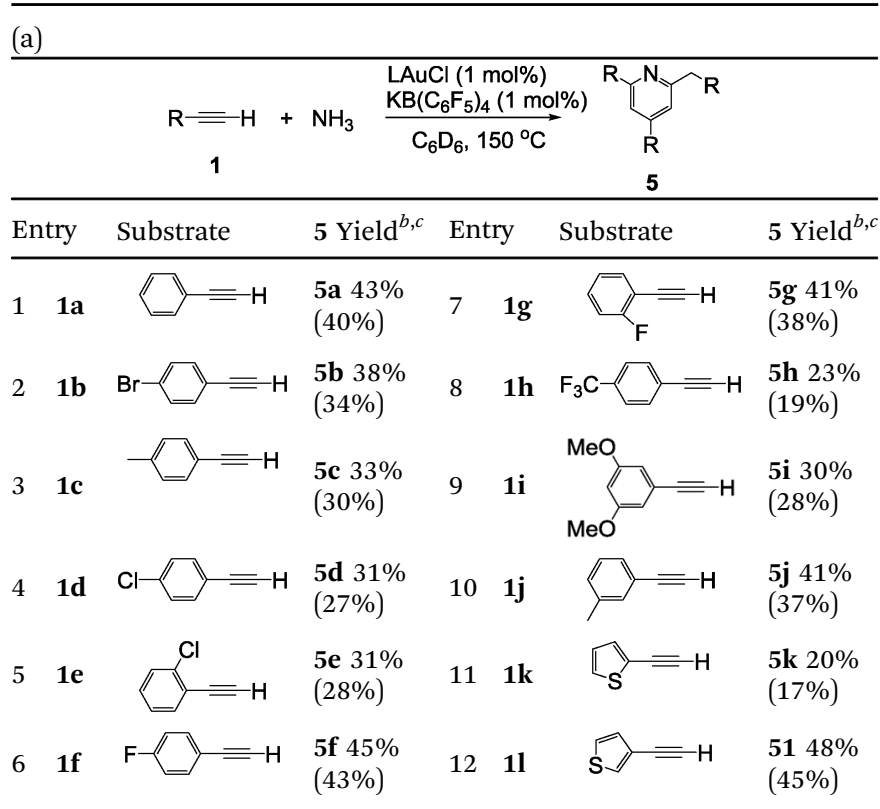

(b) ${ }^{d}$
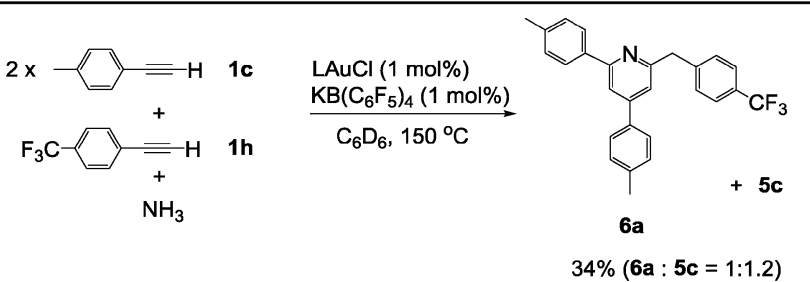

${ }^{a}$ Reaction conditions: 1 ( $\left.1 \mathrm{mmol}\right), \mathrm{NH}_{3}(0.25 \mathrm{mmol})$, LAuCl $(1 \mathrm{~mol} \%)$ and $\mathrm{KB}\left(\mathrm{C}_{6} \mathrm{~F}_{5}\right)_{4}(1 \mathrm{~mol} \%), \mathrm{C}_{6} \mathrm{D}_{6}(0.7 \mathrm{~mL}), 150{ }^{\circ} \mathrm{C} .{ }^{b}$ Yields and selectivity were determined by ${ }^{1} \mathrm{H}$ NMR spectroscopy using 1,4-di-t-butylbenzene as the internal standard. ${ }^{c}$ Isolated yields are given in parentheses. ${ }^{d}$ For other examples, see the ESI (Scheme S4).

co-products $\mathbf{5}$ assembled from the mono-component alkyne were also formed in this reaction.

To investigate the reaction mechanism, we tested the reaction of 3a with 1c in the presence of $\mathrm{LAuCl} / \mathrm{KB}\left(\mathrm{C}_{6} \mathrm{~F}_{5}\right)_{4}(5 \mathrm{~mol} \%)$ under similar reaction conditions. However, products corresponding to $\mathbf{C}$ were not detected, and only a complex mixture was obtained. We postulated that a Me-group at the imine carbon in $\mathbf{3}$ is necessary for the formal $[4+2]$ cycloaddition because it could isomerize to transient $\mathbf{3 B}$, to which alkyne $\mathbf{1}$ readily approaches due to the less steric hindrance. Meanwhile, it has been reported that the formal $[4+2]$ cycloaddition between azadienes and unsaturated compounds proceeds without any catalysts. ${ }^{29}$ Further study of the relevant gold catalysis $^{30}$ with LAuCl is currently under investigation.

The authors gratefully acknowledge financial support from Nanyang Technological University and PSF/A*STAR (SERC 1321202066) of Singapore.

\section{Notes and references}

1 (a) S. A. Lawrence, Amines: Synthesis, Properties, and Applications, Cambridge University Press, New York, 2004; (b) D. O'Hagan, Nat. Prod. Rep., 2000, 17, 435.
2 (a) A. L. Reznichenko and K. C. Hultzsch, Top. Organomet. Chem., 2013, 43, 51; (b) J. F. Hartwig, Organotransition Metal Chemistry, University Science Books, Mill Valley, CA, 2010, ch. 16.5, p.700; (c) T. E. Müller, K. C. Hultzsch, M. Yus, F. Foubelo and M. Tada, Chem. Rev., 2008, 108, 3795; (d) R. Severin and S. Doye, Chem. Soc. Rev., 2007, 36, 1407; (e) E. Mizushima, T. Hayashi and M. Tanaka, Org. Lett., 2003, 5, 3349.

3 M. B. Smith and J. March, March's Advanced Organic Chemistry, Wiley, New York, 5 edn, 2001.

4 J. Haggin, Chem. Eng. News, 1993, 71, 23.

5 M. Beller, H. Trauthwein, M. Eichberger, C. Breindl, J. Herwig, T. E. Müller and O. R. Thiel, Chem. - Eur. J., 1999, 5, 1306.

6 (a) P. Horrillo-Martínez, K. C. Hultzsch, A. Gil and V. Branchadell, Eur. J. Org. Chem., 2007, 3311; (b) K. Kumar, D. Michalik, I. Garcia Castra, A. Tillack, A. Zapf, M. Arlt, T. Heinrich, H. Böttcher and M. Beller, Chem. - Eur. J., 2004, 10, 746.

7 (a) C. Brinkmann, A. G. M. Barrett, M. S. Hill and P. A. Procopiou, J. Am. Chem. Soc., 2012, 134, 2193; (b) A. G. M. Barrett, C. Brinkmann, M. R. Crimmin, M. S. Hill, P. Hunt and P. A. Procopiou, J. Am. Chem. Soc., 2009, 131, 12906.

8 J.-S. Ryu, G. Y. Li and T. J. Marks, J. Am. Chem. Soc., 2003, 125, 12584.

9 A. Tillack, I. G. Castro, C. G. Hartung and M. Beller, Angew. Chem., Int. Ed., 2002, 41, 2541.

10 S. S. Yudha, Y. Kuninobu and K. Takai, Org. Lett., 2007, 9, 5609.

11 (a) M. Arndt, K. S. M. Salih, A. Fromm, L. J. Goossen, F. Menges and G. Niedner-Schatteburg, J. Am. Chem. Soc., 2011, 133, 7428; (b) M. Utsunomiya and J. F. Hartwig, J. Am. Chem. Soc., 2004, 126, 2702.

12 M. Utsunomiya, R. Kuwano, M. Kawatsura and J. F. Hartwig, J. Am. Chem. Soc., 2003, 125, 5608.

13 S. M. Bronner and R. H. Grubbs, Chem. Sci., 2014, 5, 101.

14 R. P. Rucker, A. M. Whittaker, H. Dang and G. Lalic, J. Am. Chem. Soc., 2012, 134, 6571.

15 J. C. Timmerman, B. D. Robertson and R. A. Widenhoefer, Angew. Chem., Int. Ed., 2015, 54, 2251.

16 F. Palacios, C. Alonso, M. Rodríguez, E. M. d. Marigorta and G. Rubiales, Eur. J. Org. Chem., 2005, 1795.

17 (a) R. He, Z.-T. Huang, Q.-Y. Zheng and C. Wang, Angew. Chem., Int. $E d$. 2014, 53, 4950; (b) S. Gupta, J. Han, Y. Kim, S. W. Lee, Y. H. Rhee and J. Park, J. Org. Chem., 2014, 79, 9094; (c) D. N. Tran and N. Cramer, Angew. Chem., Int. Ed., 2013, 52, 10630; (d) J. Zhang, A. Ugrinov and P. Zhao, Angew. Chem., Int. Ed., 2013, 52, 6681.

18 A. Laouiti, M. M. Rammah, M. B. Rammah, J. Marrot, F. Couty and G. Evano, Org. Lett., 2012, 14, 6.

19 (a) D. Pflästerer, P. Dolbundalchok, S. Rafique, M. Rudolph, F. Rominger and A. S. K. Hashmi, Adv. Synth. Catal., 2013, 355, 1383; (b) V. H. L. Wong, T. S. A. Hor and K. K. Hii, Chem. Commun., 2013, 49, 9272; (c) A. S. K. Hashmi, M. Rudolph, S. Schymura, J. Visus and W. Frey, Eur. J. Org. Chem., 2006, 4905; (d) J.-E. Kang, H.-B. Kim, J.-W. Lee and S. Shin, Org. Lett., 2006, 8, 3537.

20 R. S. Manan, P. Kilaru and P. Zhao, J. Am. Chem. Soc., 2015, 137, 6136.

21 K. Hata, Y. Segawa and K. Itami, Chem. Commun., 2012, 48, 6642.

22 (a) A. A. Tukov, A. T. Normand and M. S. Nechaev, Dalton Trans., 2009, 7015. For further examples of catalyst stabilization by bulky ligands, see: $(b)$ M. C. B. Jaimes, F. Rominger, M. M. Pereira, R. M. B. Carrilho, S. A. C. Carabineiro and A. S. K. Hashmi, Chem. Commun., 2014, 50, 4937; (c) M. C. B. Jaimes, C. R. N. Böhling, J. M. Serra-Becerra and A. S. K. Hashmi, Angew. Chem., Int. Ed., 2013, 52, 7963.

23 Experimental data for $[\mathrm{L}-\mathrm{H}]^{+}\left[\mathrm{CF}_{3} \mathrm{SO}_{3}\right]^{-}, \mathrm{LAuCl}$, and products 3, 5 and 6 are available in the ESI $\dagger$.

24 M. J. Campbell and F. D. Toste, Chem. Sci., 2011, 2, 1369.

25 A. S. K. Hashmi, Angew. Chem., Int. Ed., 2010, 49, 5232.

26 F. Palacios, C. Alonso, C. Tobillas and G. Rubiales, Heterocycles, 2004, 64, 229.

27 V. Lavallo, G. D. Frey, B. Donnadieu, M. Soleilhavoup and G. Bertrand, Angew. Chem., Int. Ed., 2008, 47, 5224.

28 A. Brossi, in The Alkaloids: Chemistry and Pharmacology, ed. G. A. Cordell, Academic Press, San Diego, 1993, vol. 43, p.119.

29 (a) S. Jayakumar, M. P. S. Ishar and M. P. Mahajan, Tetrahedron, 2002, 58, 379; (b) S. M. Weinreb and P. M. Scola, Chem. Rev., 1989, 89, 1525.

30 (a) A. Corma, A. Leyva-Pérez and M. J. Sabater, Chem. Rev., 2011, 111, 1657; (b) A. Arcadi, Chem. Rev., 2008, 108, 3266; (c) Z. Li, C. Brouwer and C. He, Chem. Rev., 2008, 108, 3239. 